\title{
Risk Factors and Incidence for Peripheral Arterial Disease in Patients with Typical Lumbar Spinal Stenosis
}

\author{
Min-Hee Han ${ }^{1}$, Dong-Hyun Lee ${ }^{1}, \mathrm{Ki}-\mathrm{Su}$ Park${ }^{1}$, Young-Seok Lee ${ }^{2}$, Kyoung-Tae Kim, \\ Joo-Kyung Sung ${ }^{1}$, Hyung-Kee $\mathrm{Kim}^{3}$, Dae-Chul Cho ${ }^{1}$ \\ ${ }^{l}$ Department of Neurosurgery, Kyungpook National University School of Medicine, Daegu, \\ ${ }^{2}$ Department of Neurosurgery, Chung-Ang University School of Medicine, Seoul, \\ ${ }^{3}$ Division of Transplantation and Vascular Surgery, Department of Surgery, Kyungpook National University \\ School of Medicine, Daegu, Korea
}

Objective: Intermittent claudication (IC) is a typical symptom of peripheral arterial disease (PAD) and lumbar spinal stenosis (LSS). In order to prevent misdiagnosis of vascular disease, it is important to know the incidence of and risk factors for PAD in patients with LSS. Therefore, the aim of our study was to evaluate the incidence of and risk factors for PAD in patients with typical and severe LSS who underwent spinal surgical treatment.

Methods: The occurrence of PAD was examined retrospectively in 171 consecutive patients with LSS and severe IC who underwent surgical treatment at our hospital from June 2012 to June 2013. Data were collected on background characteristics (sex, age) and known risk factors for PAD, such as hypertension, diabetes mellitus, smoking, hyperlipidemia, stroke, and ischemic heart disease.

Results: Of the 171 patients enrolled, 7 had an abnormal ankle-brachial index (ABI). Computed tomography angiography (CTA) was performed in these patients, and a final diagnosis of PAD was established for all 7 patients. The incidence of PAD in all patients with LSS was $4.1 \%$ (7 of 171). Stroke and ischemic heart disease were significantly more common in the LSSPAD group compared with the LSS group. Multiple logistic regression analyses with a forced-entry method revealed that age and stroke $(p<0.05)$ were independent risk factors for PAD.

Conclusion: To prevent misdiagnosis of fatal PAD, we recommend ABI be assessed in patients with LSS and history of stroke.

Key Words: Peripheral arterial disease $\cdot$ Ankle brachial pressure index $\cdot$ Lumbar spinal stenosis

\section{INTRODUCTION}

Lumbar spinal stenosis (LSS) presents with intermittent claudication (IC) in the lower extremities as a typical symptom ${ }^{26,28)}$. Peripheral arterial disease $(\mathrm{PAD})$ also presents with similar symptoms as vascular $\mathrm{IC}^{17,21)}$. Vascular IC is aggravated by ambulation and relieved by resting. Neurogenic IC, on the other hand, caused by narrowing of the neural foramen and spinal

- Received: July 3, 2014 - Revised: August 15, 2014

- Accepted: August 18, 2014

Corresponding Author: Dae-Chul Cho, MD, PhD

Department of Neurosurgery, Kyungpook National University Hospital,

130, Dongdeok-ro, Jung-gu, Daegu 700-721, Korea

Tel: +82-53-200-5649, Fax: +82-53-423-0504

E-mail: focus36@naver.com

®This is an Open Access article distributed under the terms of the Creative Commons Attribution Non-Commercial License (http://creativecommons.org/ licenses/by-nc/3.0/) which permits unrestricted non-commercial use, distribution, and reproduction in any medium, provided the original work is properly cited. canal, is aggravated by standing and relieved by sitting. However, it can be difficult to differentiate vascular and neurogenic IC due to atypical signs and variable symptoms. Therefore, when patients report claudication, it is important to correctly identify the accompanying pathology.

$\mathrm{PAD}$ includes many pathologies, such as arteriosclerosis obliterans, Buerger's disease, and acute arterial obstruction. Untreated PAD is progressive and increases the risk of severe vascular events and even death ${ }^{8,13,24)}$. Therefore, early diagnosis and treatment of PAD is important to reduce fatal or nonfatal vascular events ${ }^{17,21)}$. In order to diagnose LSS accompanied by $\mathrm{PAD}$, spine surgeons tend to examine arterial pulse in the lower extremities. However, the argument arises as to whether PAD can be ruled out only by arterial pulse examination. To establish a screening test for $\mathrm{PAD}$, ankle-brachial index (ABI) is commonly used. In previous reports, $\mathrm{ABI}$ has been found to be highly sensitive and specific for PAD screening ${ }^{10,18,20,23,24)}$.

Several authors have reported PAD in patients with $\mathrm{LSS}^{9,18,}$ 
19,27). Those reports presented the incidence of and risk factors for PAD in patients with LSS with atypical symptoms. However, there has been no study of patients with typical and severe LSS. If a patient has atypical symptoms, and diagnostic imaging shows no significant spinal canal stenosis, spine surgeons are always concerned about accompanying PAD. However, spine surgeons tend to overlook the possibility of accompanying $\mathrm{PAD}$ in patients with LSS diagnosed by typical symptoms and diagnostic imaging, such as magnetic resonance imaging (MRI).

In order to prevent misdiagnosis of vascular disease, it is important to know the incidence of and risk factors for PAD in patients with LSS. Therefore, the aim of our study was to evaluate the incidence of and risk factors for PAD in patients with typical and severe LSS who underwent spinal surgical treatment.

\section{MATERIALS AND METHODS}

The occurrence of PAD was examined retrospectively in 171 consecutive patients with LSS and severe IC who underwent surgical treatment at our hospital from June 2012 to June 2013. Patients were diagnosed with LSS by 3 neurosurgeons using neurologic examination and MRI. Three diseases were included in this study: spinal stenosis (ST), degenerative spondylolisthesis (DS) and isthmic spondylolisthesis (IS).

$\mathrm{ABI}$ was measured in all patients using previously reported methods $^{7,8)}$. ABI is the ratio of arm systolic blood pressure

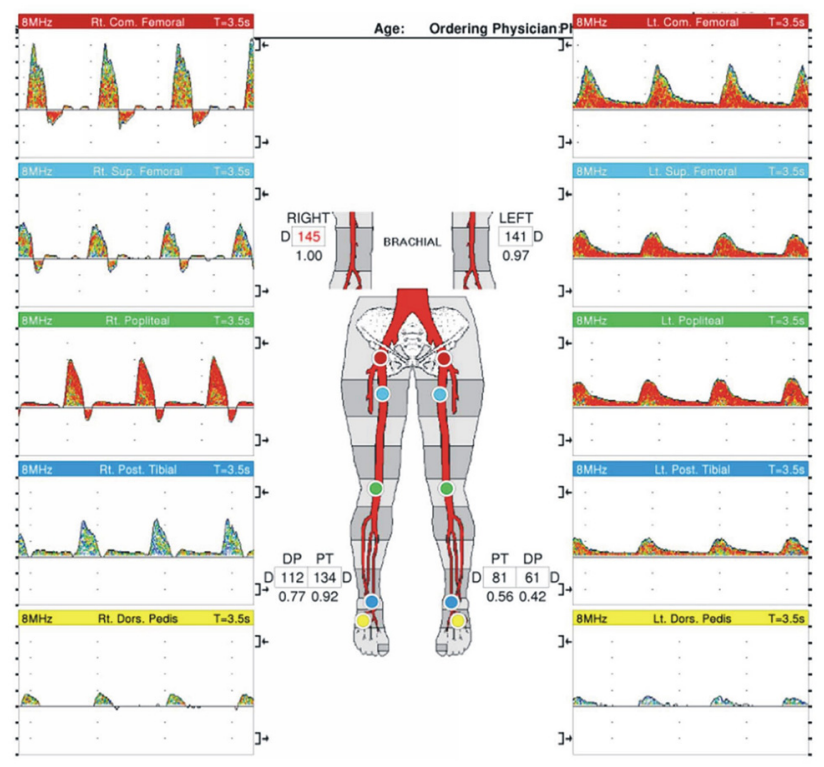

Fig. 1. An illustration of $A B I$ test at left proximal leg arterial stenoocclusive pattern. at the brachial artery to ankle systolic blood pressure at the posterior tibial or dorsalis pedis artery ${ }^{6,11,16,31)}$. ABI $<0.9$ was considered abnormal according to TransAtlantic Inter-Society Consensus (TASC) guidelines ${ }^{21)}$ (Fig. 1). All patients with abnormal ABI underwent computed tomography angiography (CTA) and consultation with a vascular surgeon (Fig. 2). Data were collected on background characteristics (sex, age) and known risk factors for PAD, such as hypertension, diabetes mellitus, smoking, hyperlipidemia, stroke, and ischemic heart disease. Quality of life (QOL) was evaluated using a visual ana$\log$ scale (VAS) and the Oswestry Disability Index (ODI) ${ }^{2,3,7,22)}$.

Patients with coexisting PAD and LSS were designated the LSSPAD group, while those with LSS but no PAD were denoted the LSS group. Using the LSS group as a control, analyses were conducted to identify the characteristics of the LSSPAD group.

To evaluate clinical characteristics at the time of enrollment, univariate analysis was performed using the Student's $t$ test (v2 test). The Mann-Whitney U-test was used to compare group means of continuous data. Multivariate logistic regression analysis was used to evaluate independent risk factors for coexisting PAD. Any variable with a $\mathrm{p}$ value of $<0.05$ on univariate analysis was included in multiple logistic regression models. Statistical significance was defined as $\mathrm{p}<0.05$. SPSS version 16.0 for Windows (SPSS Inc., Chicago, IL, USA) was used for statistical analyses. Data were presented as proportions and means \pm SDs.

\section{RESULTS}

The study population comprised 79 men and 92 women with a mean age of $64.6 \pm 8.6$ years. Of the 171 patients enrolled, $7 \mathrm{had}$ an abnormal ABI. CTA was performed in these

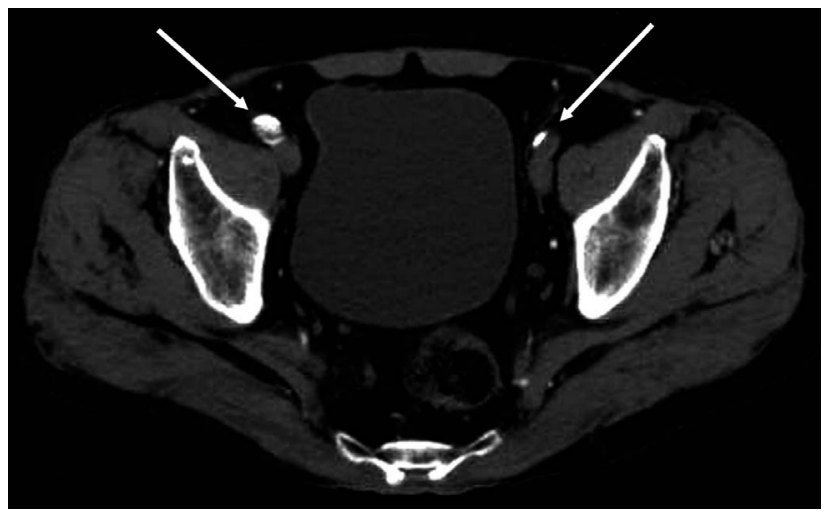

Fig. 2. An illustration of severe PAD at left iliac location. Compared with the unaffected side (right side arrow), occlusion of arterial lumen (left side arrow) was observed at the left iliac artery. 
Table 1. Comparative analysis between LSS and LSSPAD

\begin{tabular}{|c|c|c|c|c|c|c|}
\hline \multirow[b]{2}{*}{ Sex } & \multirow[b]{2}{*}{ Males } & \multicolumn{2}{|c|}{ LSS $(n=164)$} & \multicolumn{2}{|c|}{ LSSPAD (n=7) } & \multirow{3}{*}{$\begin{array}{r}\text { p-value } \\
0.25\end{array}$} \\
\hline & & $45.1 \%$ & (74) & $71.4 \%$ & (5) & \\
\hline & Females & $54.9 \%$ & (90) & $28.6 \%$ & (2) & \\
\hline $\mathrm{Age}^{*}$ & & 64.2 & \pm 8.6 & 72.3 & \pm 5.5 & $<0.01$ \\
\hline BMl & & 24.0 & \pm 2.4 & 23.0 & \pm 2.8 & 0.39 \\
\hline \multirow[t]{4}{*}{ Risk factors } & $\mathrm{DM}^{*}$ & $23.8 \%$ & (39) & $57.1 \%$ & (4) & 0.07 \\
\hline & HTN & $43.3 \%$ & (71) & $71.4 \%$ & (5) & 0.24 \\
\hline & Smoker & $15.2 \%$ & (25) & $28.6 \%$ & (2) & 0.65 \\
\hline & Hyperlipdemia & $21.3 \%$ & (35) & $28.6 \%$ & (2) & 0.31 \\
\hline \multirow[t]{2}{*}{ Medical history } & Stroke & $3.7 \%$ & (6) & $42.9 \%$ & (3) & $<0.01$ \\
\hline & $\mathrm{HHD}^{*}$ & $3.7 \%$ & (6) & $28.6 \%$ & (2) & 0.04 \\
\hline \multirow[t]{3}{*}{ Disease } & ST & $61.0 \%$ & (100) & $85.7 \%$ & (6) & \\
\hline & DS & $32.3 \%$ & (53) & $14.3 \%$ & (1) & 0.40 \\
\hline & IS & $6.7 \%$ & (11) & $0.0 \%$ & (0) & \\
\hline VAS $^{*}$ & & 7.1 & \pm 1.9 & 8.1 & \pm 0.7 & 0.16 \\
\hline ODI & & 25.0 & \pm 8.7 & 26.3 & \pm 4.7 & 0.69 \\
\hline
\end{tabular}

DM, Diabetes mellitus; HTN, Hypertension; IHD, Ischemic heart disease

Risk factors for multiple logistic regression analysis

patients, and a final diagnosis of $\mathrm{PAD}$ was established for all 7 patients. The incidence of PAD in all patients with LSS was 4.1\% (7 of 171). Six of the 7 patients diagnosed with PAD were treated with an endovascular stent, while the remaining 1 patient was recommended observation and regular followup. The results of univariate analysis of risk factors for PAD, type of disease, and other clinical parameters are shown in Table 1 . The LSSPAD group was significantly older than the LSS group $(72.3 \pm 5.5$ years vs $64.2 \pm 8.6$ years, $\mathrm{p}<0.01)$. Stroke and ischemic heart disease were significantly more common in the LSSPAD group compared with the LSS group. The other known risk factors for PAD (diabetes mellitus, hypertension, smoking history, hyperlipidemia) showed no significant differences between groups. Furthermore, there were no significant differences between groups regarding VAS and ODI scores.

Of the 171 patients with LSS, 37 (21.6\%) smoked. Among the 164 patients in the LSS group, 100 (61\%) had ST, 53 (32.3\%) had DS, and 11 (6.7\%) had IS. Among the 7 patients in the LSSPAD group, 6 (85.7\%) had ST and $1(14.3 \%)$ had DS. There were no significant differences between groups. In multivariate analysis, the entered variables were age, diabetes mellitus, preoperative VAS score, stroke and ischemic heart disease $(p<0.2)$ (Table 2). Multiple logistic regression analyses with a forced-entry method revealed that the stroke $(\mathrm{p}<$ 0.05 ) was independent risk factor for PAD. No differences in age and history of ischemic heart disease were observed between groups.
Table 2. Risk factors for PAD in patients with LSS using multiple logistic regression analysis

\begin{tabular}{lclc}
\hline \hline & Odds ratio & \multicolumn{1}{c}{$95 \% \mathrm{Cl}$} & p-value \\
\hline Age & 1.20 & $0.99-1.44$ & 0.06 \\
DM & 3.53 & $0.50-25.09$ & 0.20 \\
Stroke & 36.21 & $3.80-345.40$ & 0.00 \\
IHD & 5.39 & $0.66-44.20$ & 0.11 \\
VAS & 1.19 & $0.54-2.66$ & 0.65 \\
\hline
\end{tabular}

\section{DISCUSSION}

PAD is an atherosclerotic syndrome with a high prevalence of approximately $5.8 \%$ to $12 \%$ in older adults ${ }^{1,15)}$. High incidence of fatal or nonfatal cardiovascular events associated with PAD increases mortality. According to TASC guidelines for PAD, the mortality rate of patients with IC associated with PAD is 2 times that of patients with IC only, ${ }^{2,722)}$. Besides the risk of death, the 10-year incidence of myocardial infarction and cerebral stroke in patients with PAD are increased by about 4 and 3 times, respectively, compared with that in patients without PAD ${ }^{5,29}$. However, PAD is often misdiagnosed in older patients with LSS because it is difficult to distinguish vascular IC from neurogenic IC. Therefore, spine surgeons often overlook the possibility of PAD in patients with severe $\mathrm{LSS}^{18)}$. In a previous study, the coincidence of PAD with LSS was similar to the prevalence of PAD in older individuals $(6.7 \%)^{27)}$. Therefore, it is very important to understand the 
risk factors and to evaluate PAD in patients with LSS.

Arteriography is considered the gold standard for diagnosis of PAD. However, the use of arteriography has some limitations, including complications arising from ionizing radiation, its invasive nature, and nephrotoxic contrast media. Among substitutable tests, $\mathrm{ABI}$ is the simplest and most inexpensive ${ }^{25}$. ABI also has high sensitivity (79-95\%) and specificity (96-100\%) for screening $\mathrm{PAD}^{17)}$. Thus, we evaluated the coincidence of PAD with LSS and risk factors for PAD using ABI.

There have been several studies to evaluate the incidence of PAD in patients with LSS using ABI. Jeon et al. studied 42 patients with atypical claudication ${ }^{19)}$. Their study showed that $\mathrm{ABI}$ had high sensitivity and specificity for screening PAD in cases with atypical claudication. Twenty-two of 42 patients in their study were diagnosed with LSS and PAD, showing a high coincidence (54.8\%) between diseases. However, their study did not analyze the risk factors for PAD and was limited in that only mild cases of LSS, determined by MRI, were included. Most spine surgeons easily can doubt a hidden disease, such as PAD, in these cases. Therefore, in our study, we enrolled patients with typical symptoms, severe LSS, confirmed by MRI, who underwent decompressive surgery.

Kazuhide et al. studied 570 patients with LSS diagnosed by $\mathrm{MRI}^{27}$. They reported that $6.7 \%$ of patients had PAD confirmed by ABI. They also showed that comorbidity of diabetes mellitus, history of stroke, and history of ischemic heart disease were characteristics of patients with LSS and PAD. This was the first nationwide multicenter survey of the prevalence of PAD in patients with LSS in Japan. However, the mean VAS score of patients with LSS and PAD was 53.6 \pm 27.0 , while that of patients with LSS was $60.1 \pm 28.4$ (VAS $0-100$ $\mathrm{mm}$ ), indicating that patients with mild IC were included in this study as well as patients with severe IC who required surgical treatment. Spine surgeons occasionally make a mistake in performing surgery in patients who have radiographi- cally asymptomatic stenosis and vascular IC arising from PAD, since it is difficult to distinguish between neurogenic and vascular IC. Therefore, diagnosis of PAD is not important for patients with mild IC, but is important for patients with typical neurogenic IC and definite LSS who require surgical treatment.

We analyzed the incidence of and risk factors for PAD in patients with severe LSS and intractable IC who underwent surgical treatment. The mean preoperative VAS score of all patients was 7.2 \pm 1.9 , and there was no response to conservative treatment, such as medication, physical therapy, and epidural nerve block. Although the coincidence of PAD with LSS was not high (7 of 171 patients [4.1\%]), 6 of 7 patients had severe vascular insufficiency requiring endovascular stent surgery. Thus, it can be very dangerous if PAD is misdiagnosed in patients with LSS. Previous studies have presented several risk factors for PAD, such as old age, sex, diabetes mellitus, dyslipidemia, hypertension, smoking history, and body mass index ${ }^{15,27,30)}$. In this study, old age and history of stroke was the only significant predisposing factor for PAD. According to this result, we propose $\mathrm{ABI}$ examination in old patients with LSS and history of stroke to rule out PAD. If PAD is diagnosed, spine surgeons may be able to decide whether to perform decompressive surgery for LSS. In this decision making process, electrodiagnostic testing can be helpful to differentiate radiographically asymptomatic LSS. Although imaging studies are often not specific for LSS, electrodiagnostic testing is highly specific for diagnosis of LSS ${ }^{4,12)}$.

The strength of this study is the severe IC of the patient population, which was analyzed by multivariate logistic regression to identify the incidence of and risk factors for PAD. Diagnosis of PAD by ABI enables spine surgeons to avoid fatal vascular events and unnecessary surgery in patients with radiographically asymptomatic LSS. However, this study is limited by its retrospective nature, relatively small patient population, and short-term duration of follow-up. To further verify the incidence of and risk factors for PAD, we are currently analyzing more patients and collecting longer-term results. In addition, this study did not reveal the sensitivity and specificity of ABI because CTA was not performed in all patients. Therefore, further study is required to confirm the efficacy of ABI.

\section{CONCLUSION}

Misdiagnosis of PAD may increases the risk of severe vascular events and even death. To prevent misdiagnosis of fatal $\mathrm{PAD}$ and to avoid unnecessary surgery, we propose further evaluation should be assessed in old patients with history of stroke for diagnosis of PAD.

\section{REFERENCES}

1. Allison MA, Ho E, Denenberg JO, Langer RD, Newman AB, Fabsitz RR, et al: Ethnic-specific prevalence of peripheral arterial disease in the United States. Am J Prev Med 32:328-333, 2007

2. Alzamora MT, Forés R, Baena-Díez JM, Pera G, Toran P, Sorribes $\mathrm{M}$, et al: The Peripheral Arterial disease study (PERART/ ARTPER): prevalence and risk factors in the general population. BMC Public Health 10:38, 2010

3. Blanes JI, Cairols MA, Marrugat J: Prevalence of peripheral artery disease and its associated risk factors in Spain: The ESTIME Study. Int Angiol 28:20-25, 2009

4. Boden SD, Davis D, Dina T, Patronas N, Wiesel S: Abnormal magnetic-resonance scans of the lumbar spine in asymptomatic subjects. A prospective investigation. J Bone Joint Surg Am 72: 
403-408, 1990

5. Criqui MH, Langer RD, Fronek A, Feigelson HS, Klauber MR, McCann TJ, et al: Mortality over a period of 10 years in patients with peripheral arterial disease. N Engl J Med 326:381-386, 1992

6. de Graaff JC, Ubbink DT, Legemate DA, de Haan RJ, Jacobs MJ: Interobserver and intraobserver reproducibility of peripheral blood and oxygen pressure measurements in the assessment of lower extremity arterial disease. J Vasc Surg 33:1033-1040, 2001

7. Diehm C, Lange S, Darius H, Pittrow D, von Stritzky B, Tepohl $\mathrm{G}$, et al: Association of low ankle brachial index with high mortality in primary care. Eur Heart J 27:1743-1749, 2006

8. Diehm N, Dick F, Czuprin C, Lawall H, Baumgartner I, Diehm C: Oscillometric measurement of ankle-brachial index in patients with suspected peripheral vascular disease: comparison with Doppler method. Swiss Med Wkly 139:357-363, 2009

9. Dodge LD, Bohlman HH, Rhodes RS: Concurrent lumbar spinal stenosis and peripheral vascular disease: a report of nine patients. Clin Orthop Relat Res:141-148, 1988

10. Doobay AV, Anand SS: Sensitivity and specificity of the anklebrachial index to predict future cardiovascular outcomes: a systematic review. Arterioscler Thromb Vasc Biol 25:1463-1469, 2005

11. Greenland P, Abrams J, Aurigemma GP, Bond MG, Clark LT, Criqui $\mathrm{MH}$, et al: Prevention Conference V Beyond Secondary Prevention: Identifying the High-Risk Patient for Primary Prevention: Noninvasive Tests of Atherosclerotic Burden: Writing Group III. Circulation 101:e16-e22, 2000

12. Haig AJ, Tong HC, Yamakawa KS, Quint DJ, Hoff JT, Chiodo A, et al: The sensitivity and specificity of electrodiagnostic testing for the clinical syndrome of lumbar spinal stenosis. Spine 30:2667-2676, 2005

13. Heald C, Fowkes F, Murray G, Price J: Risk of mortality and cardiovascular disease associated with the ankle-brachial index: systematic review. Atherosclerosis 189:61-69, 2006

14. Hiatt WR: Medical treatment of peripheral arterial disease and claudication. N Engl J Med 344:1608-1621, 2001

15. Hirsch AT, Criqui MH, Treat-Jacobson D, Regensteiner JG, Creager MA, Olin JW, et al: Peripheral arterial disease detection, awareness, and treatment in primary care. JAMA 286: 1317-1324, 2001

16. Hirsch AT, Haskal ZJ, Hertzer NR, Bakal CW, Creager MA, Halperin JL, et al: ACC/AHA 2005 guidelines for the management of patients with peripheral arterial disease (lower extremity, renal, mesenteric, and abdominal aortic): executive summary a collaborative report from the American Association for Vascular Surgery/Society for Vascular Surgery, Society for Cardiovascular Angiography and Interventions, Society for Vascular Medicine and Biology, Society of Interventional Radiology, and the ACC/AHA Task Force on Practice Guidelines (Writing Committee to Develop Guidelines for the Management of Patients With Peripheral Arterial Disease) endorsed by the American Association of Cardiovascular and Pulmonary Reha- bilitation; National Heart, Lung, and Blood Institute; Society for Vascular Nursing; TransAtlantic Inter-Society Consensus; and Vascular Disease Foundation. J Am Coll Cardiol 47:1239- 1312, 2006

17. Hirsch AT, Haskal ZJ, Hertzer NR, Bakal CW, Creager MA, Halperin JL, et al: ACC/AHA Guidelines for the Management of Patients with Peripheral Arterial Disease (lower extremity, renal, mesenteric, and abdominal aortic): a collaborative report from the American Associations for Vascular Surgery/Society for Vascular Surgery, Society for Cardiovascular Angiography and Interventions, Society for Vascular Medicine and Biology, Society of Interventional Radiology, and the ACC/AHA Task Force on Practice Guidelines (writing committee to develop guidelines for the management of patients with peripheral arterial disease)--summary of recommendations. J Vasc Interv Radiol 17:1383-1398, 2006

18. Imagama S, Matsuyama Y, Sakai Y, Ito Z, Wakao N, Deguchi $\mathrm{M}$, et al: An arterial pulse examination is not sufficient for diagnosis of peripheral arterial disease in lumbar spinal canal stenosis: a prospective multicenter study. Spine 36:1204-1210, 2011

19. Jeon $\mathrm{CH}$, Han $\mathrm{SH}$, Chung NS, Hyun HS: The validity of ankle-brachial index for the differential diagnosis of peripheral arterial disease and lumbar spinal stenosis in patients with atypical claudication. Eur Spine J 21:1165-1170, 2012

20. McDermott MM, Liu K, Greenland P, Guralnik JM, Criqui $\mathrm{MH}$, Chan $\mathrm{C}$, et al: Functional decline in peripheral arterial disease: associations with the ankle brachial index and leg symptoms. JAMA 292:453-461, 2004

21. Norgren L, Hiatt WR, Dormandy JA, Nehler MR, Harris KA, Fowkes FG, et al: Inter-society consensus for the management of peripheral arterial disease (TASC II). Eur J Vasc Endovasc Surg 33:S1-S75, 2007

22. Ouriel K: Peripheral arterial disease. Lancet 358:1257-1264, 2001

23. Papamichael CM, Lekakis JP, Stamatelopoulos KS, Papaioannou TG, Alevizaki MK, Cimponeriu AT, et al: Ankle-brachial index as a predictor of the extent of coronary atherosclerosis and cardiovascular events in patients with coronary artery disease. Am J Cardiol 86:615-618, 2000

24. Resnick HE, Lindsay RS, McDermott MM, Devereux RB, Jones KL, Fabsitz RR, et al: Relationship of high and low ankle brachial index to all-cause and cardiovascular disease mortality the strong heart study. Circulation 109:733-739, 2004

25. Sorensen KE, Kristensen IB, Celermajer DS: Atherosclerosis in the human brachial artery. J Am Coll Cardiol 29:318-322, 1997

26. Takahashi K, Miyazaki T, Takino T, Matsui T, Tomita K: Epidural pressure measurements: relationship between epidural pressure and posture in patients with lumbar spinal stenosis. Spine 20:650-653, 1995

27. Uesugi K, Sekiguchi M, Kikuchi S-i, Kanayama M, Takahashi $\mathrm{K}$, Chiba $\mathrm{K}$, et al: Lumbar spinal stenosis associated with peripheral arterial disease: a prospective multicenter observational study. J Orthop Sci 17:673-681, 2012

28. Watters WC 3rd, Baisden J, Gilbert TJ, Kreiner S, Resnick DK, Bono CM, et al: Degenerative lumbar spinal stenosis: an evidence-based clinical guideline for the diagnosis and treatment of degenerative lumbar spinal stenosis. Spine J 8:305-310, 2008

29. Wilterdink JL, Easton JD: Vascular event rates in patients with atherosclerotic cerebrovascular disease. Arch Neurol 49:857-863, 1992

30. Xu D, Li J, Zou L, Xu Y, Hu D, Pagoto SL, et al: Sensitivity and specificity of the ankle-brachial index to diagnose periphe- ral artery disease: a structured review. Vasc Med 15:361-369, 2010

31. Yao ST, Hobbs JT, Irvine WT: Ankle systolic pressure measurements in arterial disease affecting the lower extremities. Br J Surg 56:676-679, 1969 